BOLETIM DE PESQUISA NELIC: Edição Especial $V^{\circ} 3$ - Dossiê Murilo Mendes

Artigos

\title{
"A inteligência":
}

Fantasma (d)e fantasia em Murilo Mendes

Evandro de Sousa 


\section{FANTASIA}

1

Anjo que precisa de outro anjo,

Espírito que vai anunciar

E ao mesmo tempo espera ser anunciado.

Anjo que segura a palma de seus braços E se contempla, desdobrando-se ao espelho.

Anjo felino que desconcerto entre sua forma e fôrma!

Regressa com as órbitas vazias

Até que possa conhecer-se um dia.

2

És de espuma e seda,

És ao mesmo tempo centelha,

Forma futura do que adivinhei em sonho.

Este ensaio foi elaborado a partir de uma dupla demanda: a escritura de uma monografia para o curso A Imaginação (2009.2), ministrado pelo Professor Doutor Raul Antelo, no Programa de Pós-Graduação em Literatura, UFSC; e também como devolução da pesquisa e leitura orientada da obra de Murilo Mendes, efetuada no transcorrer de 2009 junto ao Núcleo de Estudos Literários e Culturais (NELIC-UFSC), sob coordenação da Professora Dra. Susana Célia Leandro Scramim. É a partir desta demanda que o ensaio parece estar (e está) cindido em dois, um móbile um pouco menor concebido enquanto corpo textual, voltado para a comunicação no Simpósio Murilo Mendes (08 de março de 2010) e as divagações teóricas nestas notas finais, para cumprir o caráter de uma escritura monográfica que abarcasse o mínimo possível de teorização, ampliando assim o espaço "limitado", pela força do tempo, da comunicação.

\section{Observo eternamente \\ O horizonte convexo \\ Espiando chegares}

$$
\text { desdobrada em asa. }
$$

\section{Se me amasses}

Eu me transformaria no que sou

(Murilo Mendes, 1994, p. 387) 
No início, os sonhos eram caóticos; pouco depois foram de natureza dialética. $O$ forasteiro sonhava consigo mesmo no centro de um anfiteatro circular que era de algum modo o templo incendiado: as nuvens de alunos taciturnos exauriam a arquibancada; as caras dos últimos pendiam a muitos séculos de distância e a uma altura estelar mas eram inteiramente precisas (Borges, 2007, p.47).

Pensar a imagem da violência sem recorrer à violência do corte é um paradoxo cuja imagem imediata é recuperada no golpe que corta as cabeças, que é também um golpe engendrado a partir dela. Porém, como lê Antelo, em $A$ abstração do objeto (1997), o poeta mineiro Murilo Mendes ao defender a abstração do tempo, propõe uma relativização da violência quando opta pela hierarquização de elementos que transformados em valores se pretende "oportunamente" abstrair. O tempo sobreposto atua assim como em eco, o passado, como afirma o crítico, não tendo cessado de passar, ainda atua. Nesta direção, Susana Scramim, em Literatura do Presente (2007), afirma a partir de Giorgio Agamben e Walter Benjamin, a potencialização do anacronismo enquanto método capaz de produzir o presente. Escreverá ela assim que

\begin{abstract}
Os estudos literários que não querem ser tributários da teoria que produziu Auschwitzi não devem buscar as marcas que justamente fazem da literatura, como toda produção artística, um campo de frações segmentadas ou territórios autônomos. Buscar a categoria de presente nas obras que analisamos não tem apenas o sentido de reencontrar a história cultural de cada época nessas obras, mas sim de descobrir e reconhecer a sua vida interior, que longe de ser apenas documento histórico, pertence a um mundo textual, portanto tanto ficcional quanto histórico, porém um mundo no qual os textos declaram e ratificam a sua potência discursiva, sua potência de "ser não" (2007, p.25-6).
\end{abstract}

É partir desta cena originária teórica que tenciono desdobrar o poema Fantasia, de Murilo Mendes, publicado em Mundo Enigma (1945) ${ }^{\mathrm{ii}}$. Logo, se a imagem ${ }^{\mathrm{iii}}$ dá a ver a fissura, o rombo, ela se elabora a partir da passagem, de seu movimento dúplice. Toda imagem é imagem de um sujeito. Aristóteles concebia que poderiam existir animais não corporais, os astros por exemplos, São Tomás de Aquino ${ }^{\text {iv }}$ transpõe esta definição para conceber os anjos ${ }^{\vee}$, que chamará de L'intelligence, espírito puro (1995, p. 58). Porém, dizer d'A Inteligência, em seu caráter bélico é dizer também da estratégia, da força "violenta" de um pensamento que se elabora na esfera militar, cujo efeito no poema que aqui se analisa está paratextualmente no declínio das forças em guerra e desponta 
enquanto imagem da violência tornada potência que retorna assombrada diante da possibilidade da morte.

Dizer do Anjo, aqui, é dizer também da máquina ${ }^{\mathrm{vi}}$ da guerra: a inteligência. Mas não menos importante é a tomada paranóica que se evidencia neste gesto. Ou para recuperar Luiz Fernando Medeiros (1986), passos antes de seu encontro com a desconstrução, ao ler a série de poemas de Contemplação de Ouro Preto (1954), acerca da imagem (escreve ele "espírito") da cidade e dos ecos que transformam a leitura da tradição enquanto exercício ficcional, que o eixo de captura do poeta acontece no cerne de seu poder simbólico: a ruína ${ }^{\text {vii. }}$.

Porém se a captura nos poemas dedicados a Ouro Preto ocorre no eixo simbólico, aquilo que resta ainda enquanto signo de um tempo, em Mundo Enigma o que parece existir é uma potencialização do labirinto (do) imaginário ${ }^{\text {viii }}$. A narrativa cênica dos poemas se abre com a proposição de uma cena míticaix. Tobias e o Anjo ${ }^{x}$, que impõe um lugar de uma falta, de uma recusa ao pensamento: sempre resta algo que é impossível pensar, um lugar em que a inteligência falha. Canto obscuro, talvez do acaso e do imprevisto, para ler com ecos mallarmaicos, mas que Murilo Mendes supõe (na relação) enquanto mundo-(e)-enigma.
Neste sentido Antônio Carlos de Brito escreve estabelecendo o gesto de Murilo Mendes, enquanto "[...] sempre decidido a abolir a fronteiras entre reinos, disposto a tornar possível e do impossível, desmantelando hierarquias e embaralhando planos, dono de uma visão incomum das coisas e da poesia" (1976, p.29). O que faz do poeta um soberano autoimune em um espaço em que o enigma não é uma caixa chaveada passível de ser aberta ao desvendar da senha, mas um espaço especular e caleidoscópico onde se abre a série e se proliferam as imagens ${ }^{\mathrm{xi}}$.

Assim se este espaço em que as imagens podem aparecer pode ser tomado como a potencialidade de um "plano de trabalho" da história, é possível associar este anjo mensageiro a um certo gênio lógico, ou ainda, ao que Bachelard chamou de "esprit scientifique", por se aportar em certo "jeu dialectique de la raison", mas que também é o problema que atravessa a idéia, enquanto primeira operação não sensível do intelecto ${ }^{\text {xii }}$. Porém, se pensar é jogo, este eu também é imposto por um movimento que ser quer dialético, ainda que estranho. Tanto que je/jeu enquanto balizas são direções, mas não saídas ou entradas, são encenações, imagens palpitantes. É assim que em termos lógicos, compreensão, extensão, perfeição, são potencialidades do intelecto "alucinado"xiii em Murilo Mendes. 
Artigo - "A INTELIGÊNCIA" - Evandro de Sousa

Com o real posto em cheque, as figuras (lógicas) em cena, a partir de um problema que também é tangente a uma filosofia geométrica ${ }^{\text {xiv }}$, ou daquilo que um teorema (uma "imagem" matemática) tem a demonstrar, o mundo feito enigma constrói seu labirinto. Construindo assim uma relação que atravessa d'Alembert, Euclides, Saccheri, Lambert, Taurinos e Tilly, Bachelard poderá dizer que "Mais cependant l'elément du doute essentiel fait avec eux son apparition, encore que ce doute ne soit d'abord qu'une sorte de méthode (1968, p. 21)". Método este que atravessa ligeiramente um raciocínio pelo absurdo.

O raciocínio tomado pelo absurdo, por certo delírio enquanto saída da lira, assumido por este contructo, passa por uma esfera de certa loucura, um discurso que se dá na esfera do sentido e do não-sentido, o que se põe em jogo é a construção (efeito) que se elabora a partir da fragmentação (do movimento de fazer com que as ruínas assumam sentido, portanto, valor), assim se o poema Fantasia faz da imagem ${ }^{\mathrm{xv}}$ uma demanda em que fantasma e fantasia atravessam condições narcísicas, o sentido assim é tomado como uma aparição $^{x v i}$. O movimento encontra aporte no sujeito enquanto sujeito de sentido, tendo como paralelo o auto-erotismo e a eleição do objeto. Ou como irá afirmar Sigmund Freud, em Introducción del Narcisismo, que
Boletim de Pesquisa NELIC - Edição Especial V. 32010.1

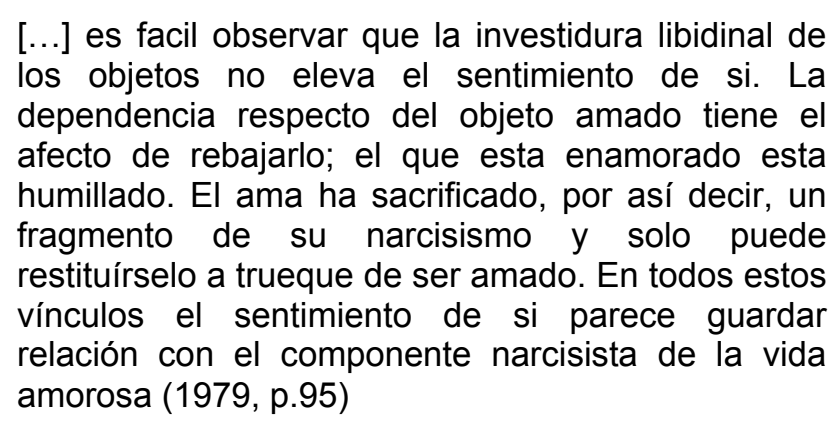

Para tanto, se impõe o lugar em que o Eu soberano não pode decidir, lugar de dispêndio e troca. $E$ assim o que proponho encontra aporte no primeiro movimento teórico de Jacques Lacan ${ }^{\text {xvii }}$, quando em $A$ agressividade em psicanálise, 1936, lê a agressividade enquanto correlato da identificação narcísica. Dirá que o amor não quer a diferença, mas busca o igual, e, assim, com a igualdade acaba por introduzir o movimento da guerra. Ora, de certa maneira, tal pensamento reflete a atmosfera discursiva dos regimes totalitários ${ }^{\text {xviii }}$ na Europa e como marca temporal (poder-se-ia dizer, capturando o teórico catalão Eugênio d'Ors: éon) é capturada no poema.

O poema devolve um anjo dúbio, anjo para além do ícone de si, o anjo que para apresentar-se precisa de um suportesuplemento: outro anjo. Alegoricamente, este lugar-anjo poderia ser comparado ao oscilar significante em que este poderia ser a demanda de outro significante, abrindo uma cadeia infinita, na qual é impossível parar a série. Os vínculos são contingentes e 
impossibilitados por uma identidade vazia, mesmo o eu é impossível na ranhura ocasionada nos sentidos. Não há a potencialidade eventual de uma "sociedade"xix em Murilo Mendes, o poema nega ${ }^{\mathrm{xx}}$ a aparição do outro.

O poema reproduz, estruturalmente, o olhar convexo e especular que propõe. É composto de dois movimentos, o primeiro composto por 4 estrofes e totalizando 8 versos, o segundo, por 3 estrofes e 9 versos. Há, ao mesmo tempo, algo que falta e algo que sobra. A leitura cruzada entre uma imagem referencial a ser refletida na superfície é de impossível decisão, uma vez que o referente se esvai. Sem tomar corpo, entre eu e o outro, a potência tornada desejo apenas impele ao movimento. O desconcerto é tomado por uma própria arritmia: as batidas de um coração desejante, mas que sem rota (e/ou sem olhos ou astros), uma vez que suas órbitas estão vazias, o lugar a ver ou percorrer (a lira) não há. A cartografia é a um lugar posto no fundo do espelho, ou ainda enquanto real impossível (ver o espelho enquanto coisa, a imagem concreta para além da imagem reflexo, imaginária e repleta de potência ficcional). $O$ movimento é "este" composto por um caractere de refinamento e incertitude, espuma e seda, mas é estopim, centelha, um prenúncio de devir. É somente assim que este devir se marca na primeira pessoa e a instaura (ainda oculta, se fazendo presente
Boletim de Pesquisa NELIC - Edição Especial V. 32010.1

na ação: o eu se marca através da desinência verbal), no primeiro verso da segunda estrofe da segunda parte: "Observo eternamente / O horizonte convexo / Espiando chegares / desdobrada em asa" (Loc. Cit). Até então a cena se desenrolava, como puro efeito, "desdobrando-se ao espelho", para instaurar assim um eu que aparece primeiramente atravessado (barrado?) e oblíquo, um "eu indireto", feito imagem imposta por um condicional: "se me amasses". Mas este movimento de "amor" é tornado erógeno, se tiver contraponto a cena que se desenrola com o primeira aparição dos anjos na poética de Murilo Mendes, em Anjos Maus, de Poesias, 1930, em que os anjos maus põem as meninas trancadas em seus quartos, diante do espelho revirando os olhos e namorando seu corpo $^{\mathrm{xxi}}$. Namorando e/ou desejando aquilo do qual está apartado: a imagem de si, o que faz que todo movimento aqui seja doloroso por atravessar este vazio enigmático, toda a força é uma força de luta (eis novamente a agressividade), como se pode perceber ainda em Poemas, nos dois últimos versos do poema A Luta: "Sou a luta entre um homem acabado /e um outro homem que está andando no ar"(Mendes, 1994, p. 105). Este homem acabado é novamente cindindo: é ruína e ao mesmo tempo perfeição, acabado por que seu tempo passou ou por ter um belo acabamento, aparência. É neste campo 
Artigo - "A INTELIGÊNCIA" - Evandro de Sousa

semântico que talvez gire e se procure o impossível desse "grande enigma" de Mundo Enigma, e sendo a fábula impossível, é preciso curvar o céu na curva convexa do espelho para possibilitar um gesto ainda. É assim que sobre a possibilidade do parecer-se e aparecer no movimento de "amor", no poema Parábola, no gesto quase que alquímico de Os quatro elementos, ano, figure assim:

\section{Parábola}

É muito difícil esconder o amor

A poesia sopra onde quer

O poeta no meio da revolução

Pára aponta uma mulher branca

E diz alguma coisa sobre o Grande Enigma

Os sábios sonham

Que estão mudando Deus de lugar.

(Mendes, 1994, p.270)

O enigma marca sua presença, é latente estando presente. O poema o faz e diz dele, mas ele é de impossível resolução. Muda o círculo do desejo, como se o desejo tornasse pura potência de desejar, o enigma é impossível por ser um enigma do enigma. O desejo impõe um lugar, talvez lírico e romântico, que é sempre frustrado, como também acontece no poema Vocação, publicado originalmente na Vocação, publicação originalmente na Revista de Antropofagia, n.14, $2^{\mathrm{a}}$
Boletim de Pesquisa NELIC - Edição Especial V. 32010.1

dentição, em 11 de julho de 1928, posto na Obra Completa por Picchio como apêndice a Poemas, por ser um poema de Murilo anterior aos anos 30. Em que se lê:

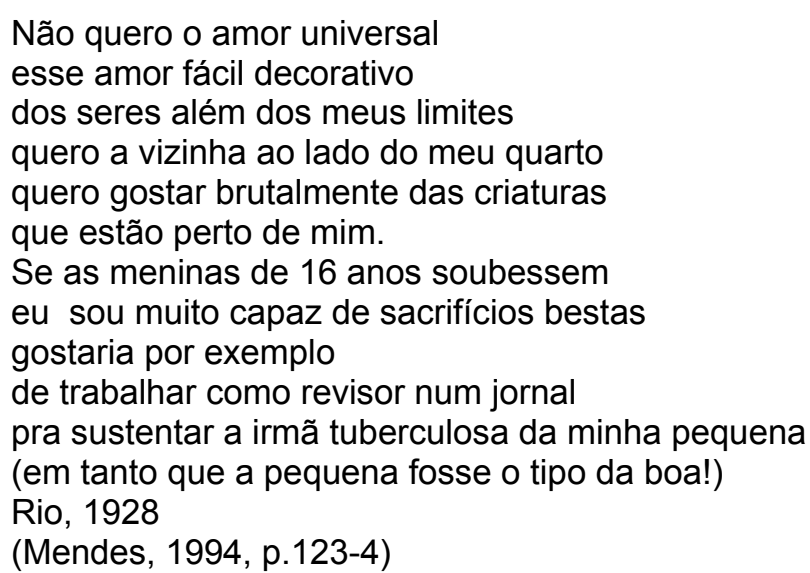

A articulação romântica ou ainda medieval, de um amor cortês, perde direção ao deparar-se com um desejo "carnal xxii". Gesto angustiado que George Bataille, em Sacrifices, colocará enquanto problema da existênciaxiii. Dúvida ou enigma que se propõe enquanto reviravolta, em Quatro elementos, no poema No cais:

\section{No cais}

Este peso de viver

Se renova como as ondas,

O amor é muito pequeno

- Só se fosse todo o amor 
Quem disse mesmo que o amor É eterno?

(Mendes, 1994, p.277)

O poema se situa na saída, no limite da abertura para o desconhecido (uma das clássicas metáforas para o mar), e do grito deste quase naufrágio, de um afogamento em si (como alude o mito do Narciso) talvez reste assim apenas o jogo, que define Murilo Mendes enquanto:

$$
\begin{aligned}
& \text { Jogo } \\
& \text { Cara ou coroa? } \\
& \text { Deus ou o demônio } \\
& \text { O amor ou o abandono } \\
& \text { Atividade ou solidão. } \\
& \text { Abre-se a mão, coroa } \\
& \text { Deus e o demônio } \\
& \text { O amor e o abandono } \\
& \text { Atividade e solidão } \\
& \text { (Mendes, 1994, p.280) }
\end{aligned}
$$

O que faz desdobrar e observar também em Fantasia um jogo suspenso e sem dialética. Anjo e jogo se metamorfoseiam em paridades de impossível distinção, Enjeu e Ange são aparições, modos de habitar o poema, adivinhando-o, sem interpretar o enigma, se atirando ao jasmineiro (feito um moço azul, quase um demônio verde, como no poema $A$ fatalidade, também de Mundo Enigma $\left.{ }^{x x i v}\right)$. É nestas referências cruzadas ${ }^{\mathrm{xxv}}$ que aparece o grande fantasma: um "eu assombrado", por si, pelo seu prazer, por uma demanda que se vira pelo avesso e raramente se vê. Assim o poema se faz corpus histérico, emite inúmeros sinais tentando significar, não obstante sua imagem fascinada é apenas a dobra do que é: uma "névoa" (ou ouriço) que ao anunciar (e enunciar) espera ser anunciado (e enunciado), colocando sua existência em um espelho partido, em que apenas resta, como Penélope e sua trama, a/à espera.

\footnotetext{
' Auschewitz parece ter aberto para além de uma topografia da discussão da violência ou um registro potencial da Segunda Grande Guerra, uma topologia acerca da potencialidade política, transformando-se em significante, ou ponto de partida, para discutir os traços (símbolos? marcas? resultados?) de uma violência limite e/ou do poder/potência posto na soberania.

ii Segundo nota filológica elaborada por Luciana Stegagno Picchio, "Compostos em 1942 e dedicados a Maria da Saudade Cortesão, os 38 poemas de Mundo enigma vieram a ser publicados na Editora Globo de Porto Alegre em 1945, juntamente com os textos de Os quatro elementos (19350) e
} 
como volume 14 da Coleção Autores Brasil. A edição, muito cuidada, tinha na capa um desenho de Vieira da Silva e no interior um retrato do poeta, reprodução do conhecido quadro de Arpad Szenes./ Mundo enigma foi incluído em 1959 na edição de Poesias 1925-1955 da José Olympio do Rio com muitas variantes que coincidem quase sempre com as correções manuscritas introduzidas posteriormente nos exemplares da edição de 1945 pertencentes ao poeta. MM continuou porém a sugerir variantes ao seu texto com correções autógrafas no seu próprio exemplar de Poesias de 1959. E é este texto, revelador do apuro a que o poeta submeteu um de seus livros mais elegantes e inspirados, o que se publica aqui [no volume de Poesia Completa e Prosa]. / Da fortuna crítica reservada a Mundo enigma pela crítica brasileira e internacional fica aqui o testemunho na Bibliografia [sectio da edição organizada por Picchio em que faz o levantamento crítico das obras]. Textos do livro, que também teve traduções integrais, como a italiana de Carlo Vittorio Cattaneo publicada na Editora Giulio Einaudi de Turim em 1976, figuram em todas as antologias do poeta (1994, p.1668)". iii G. P. Caprettini, em verbete escrito para a Enciclopédia Einaudi, para o volume dedicado ao signo, escreve que: "Imagem como cópia do verdadeiro, imagem como modo de apresentar-se da realidade, imagem como forma de conhecer. Fragmentos, mensagens da cultura, fantasias, jogos, estereótipos, recordações, vestígios... vertigem da imagem. Limites do observável, fascínio do invisível, ritmo do rito, narração do mito, simbolismo do poder, dramaticidade da visão, ternura da memória. / O campo da imagem, os seus contornos e o seu fundo nem sempre claros tendem a sobrepor-se no nosso saber, que se constitui por meio de imagens, mas que pode também ser pensado como um objecto fora de nós que dá precisamente uma «imagem» de si. / Sombras, duplos, projecções, representações, mensagens que se fixam, em virtude não só da sua eficácia simbólica, imediatamente ou a longo prazo, como se pensar fosse ver e ver também fosse pensar, numa circularidade difícil de interromper. I É precisamente o nosso pensamento que oscila entre as duas investigações dentro das quais se movem também estas páginas: a investigação do que se não se vê e está ausente, e a outra, igualmente trabalhosa, e frequentemente dramática, de uma ordem. I Remissão para o ausente e ordem (talvez 
falaciosa e provisória) do «presente» : aqui esta a ambigüidade da imagem, unda e corpus. Dela, enquanto forma de mediação, nenhuma cultura pode prescindir; e talvez seja exactamente nestas suas possibilidades, ao mesmo tempo de objecto e medium do conhecimento, da vida não apenas "simbólica», que reside seu carácter de necessidade (1994, p.177)”.

iv Raul Antelo, em Murilo, o surrealismo e a religião, aponta como lugar para o poeta mineiro entre um cristianismo escriturário e certo relativismo hermenêutico. O aparecimento assim da tradição canônica (católica) aqui se justifica e encontra aporte neste jogo entre a religião e o potencialização de um pensamento acercar do mundo, constituindo-se para além de uma pedagogia, como uma percepção e/ou filosofia.

v Segundo consta na Enciclopedia Italiana, publicada em 1935, projeto do filósofo italiano Giovanni Gentile (1875-1944) quando ministro de Mussolini durante 1922 e 1925, na entrada "Angelo", anjo detém o significado genérico de "mensageiro", por isto o tradutor grego da bíblia acabou por enfatizar esta direção de sentido ao vocábulo hebraico que significava "mensageiro ou ministro", sua função é de anunciar aos homens o desejo divino e fazer cumprir sua vontade. A enciclopédia ainda lembra que na primeira versão da Bíblia e independente desta, em grego o "anjo" possuía relações com o mundo infernal, como "demônio" era protetor dos mortos, para tanto a enciclopédia evidencia a imagem de como psicopompo guia os mortos (para todos os efeitos ainda cabe lembrar que Antônio de Carlos Brito, Cácaso, irá intitular de Eros psicopompos e hedonismo antropoplástico, publicado em Opinião, 20 de agosto de 1976). O anjo estaria assim, no cristianismo, em uma posição intermediária entre Deus e o homem, "Ma nella teologia medievale il problema degli angeli fu associato, e complicato, con quello della grazia, del libero arbitrio e della predestinazione. Gli angeli, creati buoni, poterono esercitare il libero arbitrio: di modo che alcuni furono giustamente puniti (e, privi della grazia, perseverarono irrimediabilmente nel male); altri invece, superata la prova, hanno conseguito la beatitudine. Mas si discusse se questi angeli buoni avessero conservato o no l'esercizio de loro libero arbitrio" (Enciclopédia Italiana, vol. III,p.301]. Ainda assim, não há na enciclopédia entrada para "intelligence", não obstante, há o verbete "intellecto" e "intelligenza". O primeiro consta enquanto termo filosófico que corresponde, na origem, ao termo intellectus, e analogamente a "intelligentia", o ato do intellectus. 
Há ainda aporte para uma inteligibilidade do intelecto, ao associar a intelligibilis. O verbete ainda salienta que é com Kant que o intelecto se assume como uma potência, dizendo-se então Verstand: intendimento [p.371-2]. Já intelligenza, consta de uma forma poética, ou seja, um poema em nona rima, de um autor toscano, Dino Compagni. A atribuição a este autor passou por um exercício de inteligência de C. de Batines e A. F. Ozanam, que somente com o uso de reagentes químicos conseguiram decifrar o texto do único códice completo do poema (Enciclopédia Italiana, vol. XIX, p.372).

vi Essa força da inteligência, tomada enquanto máquina, faz-me evocar Roger Bastide, que em O sagrado e o selvagem, 1973, identifica este espaço como o lugar do homem: "máquina de fábricar deuses". Para poder afirmar, numa noção de histórica como decorrência, a partir de Nietzsche e Foucault, que "o homem só se constitui como homem através de sua relação com os Deuses". Lugar este que sua declaração assume no viés da morte: Nietzsche proclama a morte de Deus esperando que Foucault proclame a morte do homem. Atravessando a esfera religiosa, relendo Durkheim, Bastide afirmará, dentro de um viés sociológico, que "[...] esse sagrado não é interpretado como surto de loucura, mas como um chamado divino" (2006, p. 255). $O$ interessante neste movimento, ainda que Bastide tencione ler as condições de uma sociedade e seus vínculos com a religião, o que não vem a ser a "relação imediata" deste ensaio, é como ele percebe o movimento duplo do transe como um modo de sair da sociedade "presente" outra. Uma saída que se dá via imaginário, uma saída tangente a imagem, a um aberto em que o racionalismo, positivista, funcionalista etc, não pode engendrar objetivamente, uma vez que o lugar palpitante desta imagem foge mediante uma solução efêmera.

vii Lição aprendida com Walter Benjamin, que também atravessou como Murilo Mendes o período que se captura neste ensaio, a ruína se apresenta enquanto o lugar de subjetivação que tenciona demonstrar a porosidade da obra e do olhar, a força do tempo e da contingência que impõe a impossibilidade de um Ser, mas recuperar apenas um fragmento, uma ruína, uma peça distorcida, um Ser não-todo, incompleto. Conceito este que corre ao encontro da categoria de "origem" proposta por Walter Benjamin, uma vez que a ruína enquanto marca postula uma saída, um movimento, ou como afirma o teórico: "aunque categoria absolutamente histórica, no tiene que ver 
nada con la génesis. Porque, en efecto, el origen no designa al devenir de lo nacido, sino lo que les nace al pasar y al devenir. El origen radica en el flujo del devenir como torbellino, engullendo en su rítmica el material de la génesis. Lo originario no se da nunca a conocer en la existencia palmaria de lo fáctico, [...] sino que concierne a su prehistoria y posthistoria (2006, p. 243)". Acerca da ruína também escreve Luiz Fernando Medeiros, sobre o poema As ruínas de Selinunte, em Siciliana, de 1954, (sobre o qual também se debruça Davi Arrigucci Junior em $O$ cacto e as ruínas) para elaborar um movimento que impõe como eixo de transformação do olhar o exercício da imaginação. Dirá ainda que Murilo Mendes estabelece uma maneira de olhar a ruína como que para preencher o mundo de correspondências, uma vez que seu gesto se elaboraria partir de um movimento de queda, sobre o qual escreve Medeiros: "Cair em desmedida e estar nascendo, eis o paradoxo muriliano. A sobrevivência se constrói como coluna colossal: entre a catástrofe e o nascimento, a sobrevivência. Sobreviver nascendo pela desmedida (1986, p.53).

viii É preciso lembrar que os primeiros escritos de Jacques Lacan, aqueles elaborados antes de 1953, data da publicação de Função da Fala e da linguagem em psicanálise, escrito fundador por apresentar os problemas teóricos que advém de seu ensino. Lacan até 1953 consegue elaborar importantes reflexões no âmbito do registro imaginário, porém "falha" em elaborar as chaves que permitiriam ler o simbólico e o real. Basta ressaltar que em 1936 publica Para além do princípio de realidade; em 1938 - A Família (versão mais próxima da versão desaparecida, de 1936, de O estádio do espelho, apresentada no congresso psicanalítico de Marienbad); em 1946, Formulações sobre a casualidade psíquica; em 1949, O estádio do espelho como formador da função do eu.

ix Jacques Lacan, em $O$ mito individual do neurótico, cujo subtítulo é Ou poesia e verdade na neurose, dirá que "O mito é o que dá uma formulação discursiva a algo que não pode ser transmitido na definição da verdade, porque a definição da verdade só pode se apoiar sobre si mesma, e é na medida em que a fala progride que ela a constitui. A fala não pode apreender a si própria, nem apreender o movimento de acesso à verdade como uma verdade objetiva. Pode apenas exprimi-la e isso de forma mítica (2008, p.13)". Dizer, portanto, de uma cena mítica aqui significa falar de um aporte concreto que realiza 
o ato intersubjetivo, no caso do poema que se lê de Murilo Mendes é a relação entre o eu e o eu-como-um-outro, mas para além disso, de uma potencialidade das relações, ou como MM escreverá em O sinal de Deus, fazendo ecoar os últimos versos do poema Fantasia, em Juízo Final do Amor, dizendo: "O quanto te amo, tu mesma não poderás saber - nem eu mesmo, pois estamos sujeitos ao tempo. / O quanto te amo, não posso te provar em atos loucos - na demonstração da grande ternura - e em múltiplos e ardentes poemas. / O quanto te amo só poderá transparecer no último dia, quando nós dois nos sentarmos à direita do Pai" (1994, p. 753-4); ou no subseqüente Amor eterno: "O amor eterno começa desde já neste mundo mesmo. Eu te amo para sempre - e quando morrermos não seremos separados pela carne: / Quando o anjo gritar NÃO HAVERÁ MAIS TEMPO / (Quando o anjo gritar NÃO HAVERÁ MAIS SEXO) / Minha essência pura se reunirá à tua e seremos um só. Tu serás a musa e o poeta-eu serei o poeta e a musa. Nascerá a poesia eterna e pura" (1994, p.754). O interessante é o lugar em que se assume a identidade última diante de uma anulação da singularidade mediante o aparecimento de um significante pleno: o pai apaziguador, ou ainda um "a-pai-ziguador", que faz cessar o embate narcísico, impondo com seu gesto soberano (de lei) o lugar da relação. Um gesto último de violência como fundamento de "parar" a violência.

x Este é o título do primeiro poema do livro que diz: "1 // Eles já caminharam muito / Ao som das trombetas pascais, / Mergulhando nas árvores / Que de perto são verdes / Mas têm uma profundidade azul. // Já o grande Peixe investiu contra o moço dançarino. / Já o deixaram atrás os muros de Ecbatana / e o perfil de Sara: / O vento varre as omoplatas da pedra. // Da castidade dos sinos / A noite agora surgiu. / O moço caminha só / Nas avenidas desertas. // 2 // O demônio moderno, áspera dama, / que pretendes enfim que eu te anuncie? / Ao fim dos sinos já encontramos a noite clássica, / E o profundo buquê de nuvens nos acena. // Nunca estaremos sós: pássaros e máquinas, / Vegetais marchando, espíritos desencadeados / Serão sempre os nossos cúmplices. / Do pálido asfalto / Se levanta a morte. / Jamais te encontrarei, / Adeus, invisível mundo" (1994, p.375). O poema oferece assim um mundo cindido, entre o mundo-mundo (conhecido? verdadeiro? "real"?), enquanto possível, habitado pelo sujeito assombrado que oferece o poema, e o mundo-enigma, invisível e impossível, porém mediante uma presença que se efetua 
paradigmaticamente por sua ausência, o mundo-mundo e o mundo-enigma se confundem e se atravessam, como Tobias e o Anjo. O mundo-enigma, na sua obscuridade, já não reflete mais, mas transformado em um movimento que é maquínico e antinatural (pássaros e aviões se equivalem), elabora um outra concepção de modernidade (que é reativada de alguma maneira com ecos rimbaudianos e baudelairianos) na "indistinção distinta" entre o eu e o outro (como ocorre na Bem como ainda há a ambivalência que acaba por fazer convergir o verde-azul), conflagrando na elaboração de um espaço em ruínas em a modernidade como áspera dama se encontra com seu demônio moderno (na contraface do encontro de Tobias com o Anjo). É como se pudesse assim dizer que o mote do poema está no fato de que as coisas são a si próprias, mas também outras.

${ }^{x i}$ Acerca de um espaço de proliferação das imagens e, ainda, da romantização do movimento da guerra, é possível recuperar no espaço criado pelo diário de Mussolini, II Diario di Guerra (19151917), em que as imagens potenciais da violência ao atravessarem a escrita do eu perdem a força turbulenta da imagem da guerra, mas ainda im-pressionadas, transformam e transtornam o eu enquanto lugar da sobrevivência como, por exemplo, pode-se perceber no capítulo intitulado Tra il Monte Nero, il Vrsig e lo Jaworcek, dia 26 de setembro, em que este escreve: " 26 Settembre. / Piove sempre. Da ventiquattro ore. lo sento l'acqua fredda che mi lava la pelle e finisce nelle scarpe. Stanotte un nostro posto di collegamento di quattro uomini e un caporale è stato catturato dagli austriaci truccati da bersaglieri. Nessuna nuova del porta-mensa Rossi. II sergente Simonelli lo dà per «disperso». Stanotte nessun ferito. Grazie all'umidità del terreno, poche bombe sono scoppiate. II capitano Mozzoni, che ha ricevuto in dono due bottiglie di cognac, lo há fatto distribuire ai bersaglieri. L'atto indica il cuore e la gentilezza dell'uomo. / Mentre scrivo, la pioggia è diventata nevischio che batte sonoramente e rabbiosamente sulla nostra tenda. II che non impedisce a Pinna e Barnini di intonare una canzone nella quale si parla di una « regina che si vorrebbe incoronare ». Romba, al intervalli, il cannone. Ora cantiamo tutti insieme:/ $E$ la bandieraera /Dei ter colo-ori/ É sempre stata la più bella, bella, bella / Noi vogliamo sempre quella /Noi vogliamo la libertà... / Distribuzione gratuita di tabaco, sigari, sigarette. Parisi m'insegna: «Non bisogna accendere in tre con lo stesso fiammifero. Altrimenti muore il più piccolo dei tre ». / Superstizioni delle trincee. Accendiamo in due. Fumo" (1934, p. 93-4). A imagem assim 
transformada em ato, mas um ato de escrita, torna-se soberana, um testemunho impossível posto entre dois. Uma imagem que se tenciona partilha da história, mas sobretudo de uma ficção tornada rito, da qual se poderia dizer "superstizioni", lugar em que o posto do eu, o olhar e o registro, tornam-se potentes, desmesurando a potencialidade de uma história universal, para uma história do particular. Uma história, neste sentido se assume como um fragmento, uma peça, um objeto, tomando enquanto sujeito (ou centro da ação) encenando sua fábula.

xii Uma leitura possível deste movimento é aferida em Martin Heidegger, em O fim da filosofia e a tarefa do pensamento, quanto este tenciona responder acerca do estado da filosofia, dirá que "Filosofia é metafísica. Pensa o ente em sua totalidade - o mundo, o homem, Deus - sob o ponto de vista do ser, sob o ponto de vista da recíproca imbricação do ente e do ser. A metafísica pensa o ente enquanto ente ao modo da representação fundadora. Pois o ser do ente mostrou-se, desde o começo da filosofia, e neste próprio começo, como fundamento (princípio). Fundamento é aquilo de onde o ente como tal, em seu tornar-se, passar e permanecer, é aquilo como é e como é, enquanto cognoscível, manipulável e transformável. O ser como fundamento leva o ente a seu apresentar-se adequado. O fundamento manifesta-se como sendo presença. Seu presente consiste em produzir para a presença cada ente que se presenta de seu modo particular. O fundamento, dependendo do tipo de presença, possui o caráter de fundar como causação ôntica do real, como possibilitação transcendental a objetividade dos objetos, como mediação dialética do movimento do espírito absoluto, do processo histórico de produção, como vontade de poder que põe valores. / O elemento distintivo do pensamento metafísico, elemento que erige o fundamento para o ente, reside no fato de, partindo do que se apresenta, representar a este em sua pre-sença e assim o apresentar como fundado desde seu fundamento (2009, p.6566)".

xiii Para validação deste lugar alucinado, que foge a uma lógica "coerente", basta lembrar o que escreve Antonio Candido, em $\mathrm{Na}$ sala de aula, no ensaio intitulado Pastor pianista/ pianista pastor, ao postular um lugar "não-convencional" para o poema de Murilo Mendes. Dirá que um poema de Mendes por vezes perturba o analista, porque não oferece uma superfície fácil para o levantamento dos recursos usados. Para tanto, enfatiza que "analisar este poema [e porque não dizer a produção deste 
poeta?] é essencialmente tentar a caracterização da sua linguagem a partir do problema das tensões, muito vivo aqui a começar pela ambigüidade do título, que pode significar 'pastor que toca piano', ou 'pastor que apascenta pianos' (2005, p. 82). Para tanto Candido elabora um esquema, que possa dar conta do poema, dizendo que o procedimento poético pode ser expresso na série: divergência $\rightarrow$ ruptura $\rightarrow$ surpresa, abrindo assim um 'outro país da sensibilidade e do conhecimento, o país em que "ele" se sente pronto para aceitar uma realidade nova. É o espaço do absurdo, do inviável (como enuncia na página 85), em que se foca Candido, para uma tentativa de travessia do "surrealismo" de Murilo Mendes, mas diferente do Meu Sonho, de Álvares de Azevedo, que Cândido analisa no citado livro sob o título de Cavalgada ambígua, o pastor de Murilo Mendes resiste a ser apenas um mundo de sonho ou pesadelo, a imagem escapa a análise, tanto a série semântica quanto a serie fônica não constituem um corpo sólido. Candido recorre a Hugo Friedrich $\left[{ }^{\star}\right]$, quanto este enuncia que a anormalidade é principal característica da poesia moderna, mas diante do enigma e do jogo que encena Murilo Mendes, Candido encontra-se diante de um impasse, o poema impede o movimento interpretativo, o que leva o crítico a afirmar que: "Estas incongruências são insolúveis, porque a despeito da possibilidade constante das palavras do poema terem sentidos figurados (notadamente os pianos, eventuais metonímias da música e, por extensão da arte), ele não se resolve, no todo, em alegoria (como a Lira 77), em símbolo (como 'Meu Sonho', ou na mistura de ambos (como em 'Fantástica'). Isso porque mais do que nesses poemas, os seus elementos centrais oferecem resistência se os quisermos traduzir em significado abstrato. A planície deserta, os pianos gritando ao luar, as sombras sem pássaros, as rosas andejas são isso mesmo, permanecem tais, vinculados pelos nexos arbitrários da visão surreal. O que há neles de abstração foi reduzido à dimensão concreta, como as "idéias rosas". E eles formam o quadro para o poeta fazer, na segunda parte, a sua reflexão, que entra em contraste com a fantasmagoria da primeira, mediadas ambas pelo pastor. Entre os pianos e os homens talvez haja uma correlação mais funda, que unificaria de maneira dialética a parte impertinente e pertinente, sugerindo que, em última instância, o efeito poético é devido a tensão entre o impossível rebanho sonoro dos pianos e a luta do homem para se exprimir (Op. Cit, p. 95)". 
$\left.{ }^{*}\right]$ Friedrich em Estrutura da Lírica Moderna, também se propõe a analisar o que chamou de Fantasia ditatorial, para falar via Hofsmannsthal dos poetas enquanto "indivíduos criativos", conceito-título que também aplica a Rimbaud. Dirá assim que: "Na poesia do século XX, com efeito, a fantasia ditatorial é a origem de todas estas transformações e destruições do mundo real. E o é a tal ponto que suas obras podem ser medidas apenas de forma heurística coma realidade e com a situação normal do homem, mas não como cognição conclusiva. É verdade que a lírica sempre cancelou a diferença entre 'é' e 'parece', submetendo seus assuntos ao poder do espírito poético. Mas o que há de moderno é que o mundo nascido da fantasia criativa e da linguagem autônoma é inimigo do mundo real. Aquela frase de Baudelaire, segundo a qual a fantasia começa com o decompor e deformar e prossegue com a recomposição de acordo com as próprias leis, confirma-se não apenas na praxe poética do século $X X$, mas também nas afirmações dos próprios poetas - e dos artistas plásticos. É notável que, nestas afirmações, sempre se divulgam expressões agressivas ou negativas. Garcia Lorca diz o seguinte de Jiménez: 'No branco infinito, que ferida pura e grande deixou sua fantasia!'. Ortega y Gasset observa: 'A alma lírica se revolta contra as coisas naturais, e as vulnera ou assassina'. Diego chama a poesia de criação daquilo que nunca veremos [com Murilo Mendes, em Fantasia, isso se diria "Forma Futura que adivinhei em sonho"]. Proust escreve: 'O artista atua como aquelas altas temperaturas sob as quais as combinações atômicas se dissociam para reunirem num agrupamento diverso [sic]. Benn fala do espírito ocidental, implicando também neste espírito a arte: 'dissolução da vida e da natureza, e reconstituição partindo de uma lei humana'. Picasso chama a pintura de um trabalho manual de cegos e entende com esta expressão a liberdade da arte frente a toda exigência objetiva. $O$ poder da fantasia, que começou a se afirmar em fins do século $X V I I I$, tornou-se no século $X X$ quase definitivo. Também a lírica tornou-se a linguagem de um mundo criado quase que exclusivamente pela fantasia que passa por cima da realidade ou a aniquila" (1978, p.202).

xiv Diante deste paralelo, pode-se pensar que em Murilo Mendes também elabora uma escrita geométrica, se capturarmos Parábola (pensando a para nela não dentro da noção cristã, mas através de uma noção matemática-arquitetônica, portanto, geométrica), escrito em 1946-1953, Convergência, publicado em 
1970, Poliedro, de 1972, e ainda Carta Geográfica, escrito entre 1965-7.

${ }^{x v}$ Ao definir as imagens com as quais o sujeito se identifica, Lacan irá buscar aporte na terminologia de Carl Jung, recuperando a noção de imago. A imago com Lacan terá o aporte de duplo escopo, por um lado acaba por impor uma imagem totalizante, uma forma (Gestalt) salvadora, mas ao mesmo turno é também uma imagem simbolizada. Neste primeiro movimento de Lacan, em que a direção de trabalho ainda não atua na distinção do registro simbólico e imaginário, ele recorre a imago, para possibilitar uma direção de olhar no duplo sentido das imagens que capturam o sujeito. Nesta primeira perspectiva, portanto, o sujeito é marcado por uma fissura que o faz encontrar na dialética de (sua) identificação, não o seu ser, o Eu pleno, mas semblantes (aparições). A identificação assim não para na imagem do eu, mas continua no seu entorno, o que possibilita que Lacan afirme que, neste processo "só se unirá assintoticamente ao devir do sujeito, qualquer que seja o sucesso das sínteses dialéticas pelas quais ele tenha que resolver, na condição de eu, sua discordância de sua própria realidade" (1998, p. 98). xvi Georges Didi-Huberman, em Phasmes, põe sua obra sobre a chancela de duas epígrafes, a saber, o Nietzsche de Fragments posthumes, e a que quero ressaltar aqui, Duchamp, em $A$ l'infinitif, quando este afirma que "L'objet est une apparition". Neste jogo de indistintos no universo que Murilo instaura, em que reconhecer sujeito e objeto é impossível, tal afirmação também recai sobre o sujeito (uma aparição no fundo do espelho, poder-se-ia evocar novamente com Lacan). Mas é sob o conceito grego de phasme, que o teórico poderá atravessar as imagens que se propõe a ler. Assim, este phasme, que significa forma, aparição, visão, fantasma, e por conseqüência presságio (1998, p.11), aparecerá como um animal (via Roger Caillois), que pertence à esfera do mito, mas não tangendo um universo platônico ("Le phasme - animal mythique, tu l'aurais compris, pour tout antiplatonisme - tire as puissance du paradoxe suivant: en réalisant une espèce de perfective imitative, il brise la hierarchie exigible de toute imitation" [Op. Cit. 18]), e assim sendo signo de dois, impõe o lugar do paradoxo. Ou como afirmará, no ensaio intitulado Images-contacts, deste mesmo compêndio, a partir da "carne [chair]" de Bataille, para entrever na ambiguidade dessas imagens sua complexidade: "Entre 
toucher quelque chose (l'empreinte comme telle) et toucher quelqu'um (dans le regard instaure), il y a toujour une complexité, une médiation, um suplement qui s'interpose" (Op. Cit. p. 34). Este lugar de convergência, entre esses esse anjo narcísico e sua sombra autonôma, em Fantasia, parece ter laço apenas em dois lugares, na potência do desejo de significar do poema, mas também no concreto da escrita: a mão do poeta que ali deposita sua sombra tornada caractere, uma impronta, caligrafia impossível, que cria a passagem do poeta.

xvii É importante fazer notar que a leitura através do que chamaria "produção teórica da psicanálise", encontra aporte em Murilo Mendes, via Roland Barthes, quando aquele cita o estudioso francês como epígrafe do livro $A$ invenção do finito, texto até então inédito, escrito quase todo em Roma, durante os anos de 1960-70, parte dos textos críticos já haviam sido publicados em catálogos, muitas vezes em italiano, como explica Picchio (In: Mendes, 1994, p.1703-04), em que figura Jacques Lacan. Eis a epígrafe: “ ‘... Je ne peux que faire mienne de la pensée de Lacan: ce n'est pas l'homme qui constitue le symbolique, mais c'est le symbolique que constitue l'homme. Quando l'homme entre dans le monde, il entre dans du symbolique qui est déjà là'. Roland Barthes"(Op. Cit. p.1298). Em muitos destes escritos teóricos Murilo Mendes deixa apreender certos movimentos que também perfazem, lateralmente, uma leitura de sua produção literária. Capturando alguns fragmentos, como exemplo, dirá ao escrever sobre Gastone Biggi, que "Sujeitos ao tempo e ao espaço, acontecenos de vez em quando de esquecer estas duas categorias, e situar-nos num território insólito, fora da faixa dos teólogos e dos poetas. Os tecnocratas de toda espécie que nos rodeiam, os 'duros', aplicam a este estado de espírito o nome de 'evasão', condenando-o severamente” (Op. Cit. p. 1299). Já ao escrever sobre Calderara, afirma que "A identidade entre espaço e imagem torna-se patente na fase não figurativa do nosso artista. A tradução visual é realizada muitas vêzes pelo monocromatismo, sem dúvida com escopo de captar a luz, revelação do fragmento e do todo, a luz-mãe, a luz-mestra sem a qual nada seria manifestado" (Op. Cit. 1301). Acerca de Rito Austero e Toteme de Capogrossi, ressalto o fragmento em que escreve que "O homem é o animal que descobriu o signo e o porta sempre como metáfora de seu senso interior de magia. Ele procura o tempo da auto-determinação e da auto-alusão, a fim de não perder no espaço das formas inumeráveis. [...] O poeta 
segundo Mallarmé acha que o mundo existe para resultar num livro. O pintor segundo Capogrossi acha que o mundo existe para explodir num signo abstrato-concreto ou quadro único, que ele estuda, lima e redimensiona através do tempo" (Op. Cit. 1302). Acerca de Carlucci: "Súbito a solidão se faz sociedade, a finura, força, a natureza, consciência, o acaso, rigor, a razão, poesia, o sonho, fenômeno plástico, o dissenso, concórdia. A linha manifesta seus movimentos profundos, sua capacidade de pensar, viajar por países insuspeitados, e tornar ao ponto inicial, carregada de surpresas. Aqui o espectador poderá participar de um jogo de espelhos, não apenas divertimento ou anotação visual, mas proposta de exame da externa tensão espaçotempo, fértil em problemas, e resolvida afinal pela luz, supremo documento de identidade do operador Carlucci" (Op. Cit. p. 1304-5). Em Dorazio e o Quadro, captura uma fala do pintor, em que Hamlet desponta como uma terceira voz incluída: "Ser ou não ser eu mesmo; valer por mim próprio ou não valer; that is the question. Que tens tu comigo? Sou irredentista, quero a minha autonomia, não amanhã: hoje, agora mesmo" (Op. Cit. p.1314). Sobre Paolo Icaro: "Sensível ao contraponto transferiu esta disciplina, talvez subconscientemente, da música para a escultura. Perigosos paralelismos esses, bem sei, mas que anoto porque, provocadores, estimulam a inteligência dos contrastes" (Op. Cit. p. 1318). Postula uma experiência do tempo em Alberto Magnelli ao escrever que "O homem de hoje tem atrás de si a soma de todas as experiências passadas, podendo medi-las e julgá-las. Possui todos os elementos para análise em extensão e profundidade do mundo em que vive. A física atual concebe o universo como um sistema de energia em contínua expansão. Essa teoria não pode deixar de alterar nossa maneira de perceber os fenômenos e, por tangência, o fenômeno artístico" (Op. Cit. p. 1319). Em Mário Padovan, com aporte novamente em Barthes, elabora: "Uma das operações fundamentais realizadas pelo homem moderno consiste em transformar a natureza em cultura. A natureza sofreu o duplo impacto do cérebro humano e da máquina, que, de resto, é construída pelo cérebro. Roland Barthes escreveu que assim como o grego antigo prestava o ouvido ao frêmito da natureza, o homem moderno é atento ao 'natural' da cultura. Claro que os poetas e os artistas encontram-se na primeira linha desta operação que alterou o conceito de natureza e da planificação das novas estruturas. Bastaria lembrar dois únicos nomes, o de Baudelaire, cuja idéia de artificialismo oposta à de natureza impregna toda sua obra, e Picasso, que declarou não existirem 
pés na natureza" (Op. Cit. p.1326). O que quero com estas capturas é mostrar guinadas e desenvolvimentos, apontes e aportes temporais elaborados afecciosamente em torno do centro (do "eu") destas escrituras, que aqui quero indistintas, que é Murilo Mendes.

xviii Lacoue-Labarthe e Nancy, evidenciam em O Mito Nazista, certa inquietação do "presente" com nosso passado recente, escrevem, abrindo a proposição do problema que abordam, que "De uma maneira geral o nosso presente está longe de estar em paz com seu passado recente nazista e fascista, ou ainda com seu passado stalinista e maoísta ainda mais recente (e talvez olhando mais de perto, reste-nos mais coisas a esclarecer do primeiro do que do segundo; ao menos este último não se produziu na 'nossa' Europa do Oeste (2002, p.9-10)". A abordagem elaborada assim por estes franceses, atravessa a funcionalização do mito e das identidades, o que é pano de fundo deste ensaio, assim, a partir do dado histórico, LacoueLabarthe e Nancy esclarecem que sua retomada ao problema nazista é dada justamente pelo enfático retorno que esta cena tem tido, ao reconhecer que '[...] existe no 'ar do tempo' um clamor ou uma espera surda de algo como uma representação, uma figuração, a saber uma encarnação do ser ou do destino da comunidade (essa palavra por si própria já parece despertar esse desejo). Ora, é justamente dessa identificação simbólica (ou 'imaginária', segundo o léxico que escolhermos: em todo caso, por meio de imagens, símbolos, narrativas, figuras e também de elementos que o portam ou os exibem) que o fascismo em geral alimentou-se de modo superabundante: o nazismo representa, nesse sentido, como nós esperamos ter demonstrado, a atualização dos caracteres fundamentais dessa função identificadora" (Op. Cit. p. 11-12). Tendo aberto esta direção de sentido, pode-se assim encaminhar o rombo aberto no neste anjo dublo, dúbio e fantasmático no aberto do significado do poema de Murilo Mendes, através de uma condição lucíferina (decadentista também poderia fazer se aparecer, para devolver um fantasmático Mallarmé) e infernal (o que também condiz com os, já citados, ecos rimbaudianos e baudelairianos), mas em seu caráter nobre, o que ao seu turno acaba devolvendo a figura de um Prometeu-Lucífer, uma vez que o anjo caído também é ao seu turno portador de uma luz, ao passo que também teria como maior pecado a vaidade e a soberba, como também figura no Novíssimo Prometeu, poema d'O Visionário (publicado em 1941), cujo desejo aberto na cena 
assim se desenrola: "Eu quis acender o espírito da vida, / Quis refundir meu próprio molde,/ Quis conhecer a verdade dos seres, dos elementos; / Me rebelei contra Deus, / Contra o papa, os banqueiros, a escola antiga, / Contra minha família, contra meu amor, / Depois contra o trabalho,/ Depois contra a preguiça, / Depois contra mim mesmo, / Contra minhas três dimensões: // Então o ditador do mundo / Mandou me prender no Pão de Açúcar: / Vêm esquadrilhas de aviões / Bicar o meu pobre fígado. / Vomito bílis em quantidade, / Contemplo lá embaixo as filhas do mar / Vestidas de maiô, cantando sambas, / Vejo madrugadas e tardes nascerem / - Pureza e simplicidade da vida! - / Mas não posso pedir perdão" (Mendes, 1994, p.237-8). Assim entre o que acontece e o que se espera, evento e advento, o lugar da poética aqui se abriria no reconhecimento de uma função/demanda, cuja questão também salienta LacoueLabarthe e Nancy, ao indagar se que esta "[...] questão é saber em que consiste a operação de identificação e se é tendo em vista a confecção de um mito que ela deve hoje, novamente ser empregada - ou se pelo contrário, a função mítica, com seus efeitos nacionais e populares, éticos e estéticos, não é aquilo contra o que a política deve ser agora reinventada (incluindo aí aquilo que ela exige talvez na ordem do 'figural')" (Op. Cit. p.14).
Este livro traz ainda, na edição brasileira logo após a folha de rosto, citação de Giorgio Agamben (que no caso não é atribuída ao teórico italiano, mas vem sem identificar seu autor), retirada de $O$ que resta de Auschwitz, texto que se insere na cena fazendo diálogo com os teóricos franceses.

${ }^{\text {xix }}$ Por inserir numa série armada, cujo movimento é o sujeito, a potência de uma vontade, a possibilidade do aparecimento fantasmático de um "eu", o poema impede a ascensão, gira em seu vazio de sentido, onde as referências são elas mesmas, mas também alheias. Por isso, talvez, Antonio Candido não consiga enunciar suas bases interpretativas acerca de Murilo Mendes, uma vez que o projeto do crítico busca a constituição de uma comunidade, que é impossível em Murilo Mendes, para tanto basta lembrar que as balizas teóricas de Candido são alçadas por valores formadores da literatura tanto quanto da sociedade, neste sentido basta capturar as funções armadas em Literatura e Sociedade, que poderiam ser resumidas a partir do segundo parágrafo do capítulo VII do citado livro, em que escreve o crítico que "Com efeito, entendemos por literatura, neste contexto [de participação social], fatos eminentemente associativos; obras e atitudes que exprimem certas relações dos 
homens entre si, e que, tomadas em conjunto, representam uma socialização dos seus impulsos últimos íntimos. Toda obra é pessoal, única e insubstituível, na medida que brota de uma confidência, um esforço de pensamento, um assomo de intuição, tornando-se uma 'expressão'. A literatura, porém, é coletiva, na medida que requer uma certa comunhão de meios expressivos (a palavra, a imagem), e mobiliza afinidades profundas que congregam os homens de um lugar e de um momento - para chegar a uma 'comunicação' (2000,p. 127). É importante salientar que Luckács não potencializa uma leitura quando a noção central de comunidade rui, as duas grandes guerras potencializa(ra)m o ostracismo desses "eus", tanto que caberia voltar sobre Candido a crítica que dirige Lacan a Jean Piaget acerca da crença na comunicação: "Sob o nome de socialização da linguagem, a relação com o outro é ali retratada como a chave do ponto de inflexão entra a linguagem egocêntrica e a linguagem acabada em sua função. Esse ponto de inflexão não é o ponto de um efeito, de impacto efetivo, mas pode ser denominado desejo de comunicar. Aliás, é justamente por esse desejo não se realizar que toda a pedagogia de Piaget vem instalar aí seus aparelhos e seus fantasmas. Muito insatisfeito, em suma, com o fato de a criança só parecer compreendê-lo pela metade, ele acrescenta que as crianças não se compreendem bem nem mesmo entre si (Lacan, 2005, p. 311)". Ainda acerca da literatura, basta colocar na contra-face o empreendimento elaborado no pós-guerra, por Maurice Blanchot, ao evidenciar tanto o caráter solitário da obra, quanto seu movimento de "Noli me legere". O movimento é, ao contrário da comunhão para uma totalidade de uma comunidade, ao revés, para abandono do eu e da obra, por isso dirá Blanchot que "La solitude qui arrive à l'écrivain de par l'oeuvre se revele en ceci: écrire est maintenant l'interminable, l'incessant. L'écrivain n'appartient plus au domaine magistral où s'exprimer signifie exprimir l'exactitude et la certitude des choses et des valeurs selon le sens de leurs limites. Ce qui s'écrit livre celui qui doit écrire à une affirmation sur laquelle il est sans autorité, qui est elle-même sans consistance, qui n'affirme rien, qui n'est pas le repôs, la dignité du silence, car elle est ce qui parle encore quand tout a été dit, ce qui ne precede pas la parole, car elle l'empêche plutôt d'être parole commençante, comme elle lui retire le droit et le pouvoir de s'interrompe. Écrire, c'est briser le lien qui unit la parole à moi-même, brises le rapport qui, me faisant parler vers « toi », me donne parole dans l'entende que cette parole reçoit de toi, car elle t'interpelle, elle est 
interpellation qui commence en moi parce qu'elle est finit en toi. Écrire, c'est rompre ce lien. C'est, en outre, retirer le langage du cours du monde, le dessaisir de ce qui fai de lui un pouvoir par lequel, si je parle, c'est le monde qui se parle, c'est le jour qui s'édifie par le travail, l'action et le temps (1955, p.16-7).

xx Talvez trazendo Roger Caillois à cena, com certa dose de antropofagia, poder-se-ia dizer que o outro aqui é devorado. Ao eleger a imagem do louva-a-deus para ler o mito, Caillois insere, em $O$ mito e o homem, um lugar sinistro (talvez sádico) para a imagem: lê o mimetismo do inseto enquanto puro artifício, pondo-se entre a criação e adivinhação (s/ data, p. 38), entre o que se sonhava e via sonho se tornava realidade. Ao perceber neste outro uma identificação antropomórfica, o homem se desrealiza através de uma função que tange sua afetividade . Ou como diz Caillois: "Ora o louva-a-deus não lembra apenas a forma humana pelo seu aspecto geral [morfologia de sua imagem], mas, único entre os insectos possuidores de larvas de odonatos, ele tem, tal como o homem, a faculdade de virar a cabeça para seguir com os olhos aquilo sobre que fixou a atenção [neste ponto Caillois abre nota de rodapé citado J. Rostand, La vie des libellules, de 1935: 'O louva-a-deus é o único entre os insectos a dirigir o olhar; inspecciona, examina, quase que tem uma fisionomia']. Talvez não seja preciso explicar a atribuição de um mau-olhado a estes animais. Os outros podem apenas ver, estes podem observar" (Op. Cit. p. 40). O louva-a-deus será assim tratado como um "assassino apaixonado", no ato de paixão devora o outro, o traz para dentro de si. Alegoria que de alguma forma faz despontar uma direção nesta função narcísica que se desenha em Fantasia, habitar assim a imagem é dotar o "eu" de sua própria figuração.

xxi “Anjos Maus // Os anjos do mal são verdes e grandes /se escondem nas nuvens nas dobras do céu / perturbam os lares destroem cidades / nem miram coitados a bola do sol. // De tarde insinuam com jeito coisas maliciosas / à mulher que passa acariciando os seios /e às meninas que ficam trancadas no quarto / o dia inteiro no espelho revirando os olhos, / namorando o corpo delas, / depois a sociedade vai por água abaixo. // São fortes e altos, não é sopa não, / têm dentes de pérola, boca de coral. / Os aviadores partem para combatê-los e morrem. IAs viúvas dos aviadores não recebem o montepio" (Mendes, 1994, p. 98-9). 
xxii Com as discussões e considerações elaboradas por Michel Foucault poder-se-ia perguntar se aqui não se situaria o grande enigma, isto é, tendo em mente que projeto de pesquisa do historiador, em Histoire de la sexualité, é perceber a sexualidade concebida como experiência, dado que ele entende por experiência a correlação, em uma cultura, entre domínios do saber, tipos de normatividade e formas de subjetividade, propondo assim uma arqueologia do sujeito pelo viés da experiência da sexualidade. $O$ interessante é a maneira como este maneja a figura do herói cristão enquanto "modelo de abstenção", ao escrever: "L' héros vertuex qui est capable de se détourner du plaisir comme d'une tentation dans laquelle il sait ne pas tomber est une figure familière au christianisme, come a été courante l'idée que cette renunciation es capable de donner accès à une experience spirituelle de la vérité et de l'amour que l'activité sexuelle exclurait. Mais est également connue de l'Antiquité païenne la figure de ces athlètes de la tempérance qui sont assez maîtres d'eux-mêmes et de leurs convoitises pour renoncer au plaisir sexuel" (1984, p.26). Assim é que tomando um conceito bataillano, a noção de despesa, Foucault a capitaliza e a transpõe ao ato quando afirma, situando-a, que é em " L'acte sexuel arrache au corps une substance qui est capable de transmettre la vie, mais qui ne la transmet que parce que elle-même est liée à l'existence de l'individu et qu'elle em port une part. Em expulsant as semence, l'être vivant ne se contente pas d'évacuer une humeur em excès : il se prive d'élements qui sont d'un grand prix pour sa propre existence" (Op. Cit. p. 146), o caráter precioso do esperma, enquanto dotado de "alguma vida" por transmiti-lo, transforma-o numa parte deste enigma. Mas será na abertura do primeiro volume de Histoire de la sexualité, ao reiterar que a insígnia, marca de uma sociedade vitoriana e acentua que se vivêssemos ainda na regência de tais valores "A pudicícia imperial figuraria no brasão de nossa sexualidade, contida, muda, hipócrita", seria tomada como modelo e relegaria o discurso sexual em duas direções, nos tempos subseqüentes, seja ao divã, seja ao confessionário. "Diz-se que no início do século XVII ainda vigorava uma certa franqueza. As práticas não procuravam o segredo; as palavras eram ditas sem reticência excessiva e, as coisas, sem demasiado disfarce; tinha-se com o ilícito uma tolerante familiaridade. Eram frouxos os códigos de grosseria, da obscenidade, da decência, se comparados com o século XIX. Gestos diretos, discursos sem vergonha, transgressões visíveis, anatomias mostradas e facilmente misturadas, crianças astutas 
vagando, sem incômodo nem escândalo, entre os risos dos adultos: os corpos "pavoneavam" (1988, p. 9). Assim, com Foucault, o enigma seria procurado neste silenciamento do corpo, uma vez que "'Se o sexo é reprimido, isto é, fadado à proibição, à inexistência e ao mutismo, o simples fato de falar dele e de sua repressão possui como que um ar de transgressão deliberada. Quem emprega esse linguagem coloca-se, até certo ponto, fora do alcance do poder; desordena a lei; antecipa, por menos que seja, a liberdade futura" (Op. Cit. p.12). Assim, uma poesia que se produzisse na esfera deste discurso seria uma poesia que ao por o corpo em liberdade se poria em liberdade, para além dos interditos.

xxiii Logo no início do artigo, escreve Bataille que: "Moi, j’existe, suspendu dans um vide réalise - suspendu à ma propre angoisse - différent de tout autre être et tel que les divers événements qui peuvent atteindre tout autre et noi moi rejettent cruellement ce moi hors d'une existence totale. Mais, em même temps, je considere ma venue au monde - qui a dépendu de la naissance et de la conjonction - il existe en effet un moment unique em rapport avec la possilité de moi - et ainsi apparaît l'improbabilité infinie de cette venue au monde. Car si la plus infime différence était survenue au cours des événements successifs don't je suis un terme, à la place de ce moi intégralement avide d'être moi, il y aurait eu « un autre » (1970, p.89). Assim, entre gozo e jogo, numa improbabilidade infinita que atravessa o imperativo da existência do "eu sou", enquanto presença suspensa que aparece o eu e sua angústia, segundo Bataille, cuja estrutura estaria próxima do non-sense, e que se faria figurar novamente em outro complexo de ambivalências: "Un choix entre des représentations opposées devrait être lié à la solution inconcevable du problème de ce qui existe : qu'exite$t$-il en tant qu'existence profonde libérée des formes de l'apparence? Le plus souvent la réponse hâtive et inconsidérée est fait comme si la question qu'y a-t-il d'imperatif (quelle est la valeur morale) et non qu'existe-t-il avait été posée. Dans les autres cas - où la philosophie est frustée de son object - la réponse non moins hâtive n'est que l'élusion parfait et incomprehensive (et non la destruction) du problème : si la matière est représentée comme existence profonde" (Op. Cit. p. 90). Assim articula-se o problema da representação que atravessaria, antes de uma essência e de uma permanência, a oscilação daquilo que vem da morte e aparece em uma estrutura 
do eu [moi] e de como este reage para além da aparência lógica de que "isto" existe.

xxiv "A FATALIDADE // Um moço azul atirou-se de um jasmineiro / Os sinos perderam a fala / A fértil sementeira de espadas / Atrai o olhar das crianças// Não existem mais dimensões / Nem cálculos possíveis / O vendo caminha / A léguas da história / As rosas quebram a vidraça. // Demoliram uma mulher / A sons de clarinete. // Escrevo para me tornar invisível, / Para perder a chave do abismo" (Mendes, 1994, p. 388).

xxv Jogo de referências cruzadas que ainda pode ser capturado em Roland BARTHES par roland barthes, quanto (um d') este(s), ambos e nenhum, abre o livro lembrando, em meio as fotografias, que: "Voici, pour commencer, quelques images: elles son la part du plaisir que l'auteur s'offre à lui-même en terminant son livre. Ce plaisir est de fascination (et par là même égoïste). Je n'ai retenu que les imagens me sidèrent, sans que je sache pourquoi (cette ignorance est le propre de la fascination, et ce que je dirai de chaque image ne sera jamais qu'imaginaire). / Or, il faut reconnaître, ce son seulement les imagens de ma jeunesse qui me fascinent. Cette jeunesse ne fut pas malhareuse, grâce à l'affection que m'entourait; elle fut néanmoins assez ingrate, pas solitude et gêne matérielle. Ce n'est donc pas la nostalgie d'un temps heureux qui me tient enchanté devant ces photographies, mas quelque chose plus trouble. / Lorsque la méditation (la sidération) constitue l'image en étre détaché, lorsqu'elle en fait l'objet d'une joissance immédiate, elle n'a plus rien à voir avec la réflexion, fût-elle rêveuse, d'une identité; elle se tourment e s'enchante d'une vision qui n'est nullement morphologique (je ne me ressemble jamais), mais plutôt organique. Embrassant tout le champ parental, l'imagerie agit comme un médium et me rapport avec le " ça " de mon corps; elle suscite en moi une sorte des rêves obtus, dont les unites son des dents, des cheveux, un nez, une maigreur, des jambs à long bas, qui ne m'appartiennent pas, sans pourtant appartenir à personne d'autre qu'à moi: me voice dès lors en état d'inquiétante familiarité: je vois la fissure du sujet (cela même dont il ne peut rien dire). II s'ensuit que la photographie de jeunesse est à la fois très indiscrète (c'est mon corps du dessous qui s'y donne à lire) et très discrète (ce n'est pas de « moi » qu'elle parle). / [.......]/ L'imaginaire d'images sera donc arrête à l'entrée dans la vie productive (qui fut pour moi la sortie du sanatorium). Un autre imaginaire s'avancera alors: celui de l'écriture. Et pour que cet imaginaire-là puísse se 
déployer (car telle est l'intention de ce livre) sans être jamais retenu, assuré, justifié par la représentation d'un individu civil, pour qu'il soit libre de ses signes propres, jamais figuratifs, le texte suivra sans images, sinon celles de la main qui trace" (1975, p.5-6, o uso do itálico pertence a Barthes).

\section{Referências (Inventário Fantasmático)}

AGAMBEN, Giorgio. O que resta de Auschwitz: o arquivo e a testemunha (Homo Sacer III). Trad. Selvino J. Assmann. São Paulo: Boitempo, 2008.

ANTELO, Raul. A abstração do objeto. In: Revista USP. n.33. São Paulo: Edusp, Março/Maio, 1997, p. 201-7.

ANTELO, Raul. Murilo, o surrealismo e a religião. In:

Ausências. Florianópolis: Editora da Casa, 2009, p. 65-86.

BACHELARD, Gaston. Le nouvel esprit scientifique. $10^{\text {ème }}$ édition. Paris: Presses Universitaires de France, 1968.

BASTIDE, Roger. O sagrado e o selvagem. Trad. Dorothée de Bruchard. São Paulo: Companhia das Letras, 2006.

BARTHES, Roland. Roland BARTHES par roland barthes. Paris: Seuil, 1975.
BATAILLE, Georges. Oeuvres Complètes: Premiers écrits (1922-1940). Paris: Gallimard, 2007, v. I.

BENJAMIN, Walter. El orígen del 'Trauerspiel' alemán. In: Obras. V. 1. Ed. Rolf Tiedemann e Hermann Schweppenhäuser, trad. esp. de Alfredo Brotons Muñoz. Madrid: Abada, 2006.

BLANCHOT, Maurice. L'espace littéraire. Paris: Gallimard, 1955.

BORGES, Jorge Luís. As ruínas circulares. In: Ficções. Trad. Davi Arrigucci Jr. São Paulo: Companhia das Letras, 2007, p.46-52.

CAILLOIS, Roger. O homem e o mito. Trad. José Calisto dos Santos. Lisboa: Edições 70, s/ data.

CANDIDO, Antonio. Literatura e sociedade. 8.ed. São Paulo: T.A. Queiroz/Publifolha, 2000.

CANDIDO, Antonio. Na sala de aula: caderno de análise literária. São Paulo: Ática, 2005.

CAPRETTINI, C. G. Imagem. In: ENCICLOPÉDIA EINAUDI: Signo. Lisboa: Imprensa Nacional, Casa da Moeda, 1994, volume 31, p. 177. 
BRITO, Antônio Carlos de. Murilo Mendes: Eros psicopompos e hedonismo antropoplástico. In: Opinião, 20 de agosto de 1976, p.29.

DIDI-HUBERMAN, Georges. Phasmes: essais sur l'apparition. Paris: Les Éditions de Minuit, 1998.

Enciclopedia Italiana: di Scienze, Lettere ed Arti. Roma: Instituto della Enciclopedia Italiana, Fondata da Giovanni Treccani, 2.ed., 1949, vol.III e vol. XIX.

FOUCAULT, Michel. Histoire de la sexualité II: l'usage des plaisirs. Paris: Gallimard, 1984.

FOUCAULT, Michel. História da sexualidade I: a vontade de saber. Trad. Maria Thereza da Costa Albuquerque e J. A. Guilhon Albuquerque. Rio de Janeiro: edições Graal, 1988.

FREUD, Sigmund. Sigmund Freud obras completas. Buenos Aires: Amorrortu Editores, 1979, vol. XIV.

FRIEDRICH, Hugo. Estrutura da Lírica Moderna (da metade do século XIX a meados do século $X X$ ). Trad. Marise $M$. Curione. São Paulo: Duas Cidades, 1978.

HEIDEGGER, Martin. Sobre a questão do pensamento. Trad. Ernildo Stein. Petrópolis: Editora Vozes, 2009.

LACAN, Jacques. Escritos. Rio de Janeiro: Jorge Zahar, 1998.
LACAN, Jacques. A angústia (1962-1963). Trad. Vera Ribeiro. Rio de Janeiro: Jorge Zahar Ed. , 2005.

LACAN, Jacques. O mito individual do neurótico: ou de poesia e verdade na neurose. Trad. Cláudia Berliner. Rio de Janeiro: Jorge Zahar Editor, 2008.

LACOUE-LABARTHE, Philippe. NANCY, Jean-Luc. O mito nazista: seguido de $O$ espírito do nacional socialismo e o seu destino (por Philippe Lacoue-Labarthe). Trad. Márcio SeligmanSilva. São Paulo: lluminuras, 2002.

MEDEIROS, Luiz Fernando. Contemplação de Murilo. In: Revista Tempo Brasileiro. n. 85. Abril/Junho, 1986, p. 49-63.

MENDES, Murilo. Poesia Completa e Prosa. Org. Luciana Stegagno Picchio. Rio de Janeiro: Nova Aquilar, 1994.

MUSSOLINI, Benito. Dall'Intervento al Facismo (15 Novembre 1914 - 23 Marzo 1919). Milano: Ulrico Hoepli Editore, 1934-XII. SCRAMIN, Susana. Literatura do Presente: história e anacronismo dos textos. Chapecó: Argos, 2007.

THOMAS, Saint. L'être et l'essence / De ente et essentia. Trad. Catherine Capelle. Paris: Librairie Philosophique J. Vrin, 1995.

WEINTRAUB, Fabio. Murilos de vento: cognição e vertigem em Murilo Mendes. In: Cult. n. 46, ano 5, 2001, p. 13 - 17. 